\title{
ina \\ A Boussinesq-Type Model for Nonlinear Wave-Heaving Cylinder Interaction
}

\author{
Theofanis Karambas * (D) and Eva Loukogeorgaki
}

\author{
Department of Civil Engineering, Aristotle University of Thessaloniki, 54124 Thessaloniki, Greece; \\ eloukog@civil.auth.gr \\ * Correspondence: karambas@civil.auth.gr; Tel.: +30-2310-995885
}

check for updates

Citation: Karambas, T.;

Loukogeorgaki, E. A

Boussinesq-Type Model for

Nonlinear Wave-Heaving Cylinder

Interaction. Energies 2022, 15, 469.

https://doi.org/10.3390/en15020469

Academic Editor: Nikolaos

P. Theodossiou

Received: 27 October 2021

Accepted: 4 January 2022

Published: 10 January 2022

Publisher's Note: MDPI stays neutral with regard to jurisdictional claims in published maps and institutional affiliations.

Copyright: (C) 2022 by the authors. Licensee MDPI, Basel, Switzerland. This article is an open access article distributed under the terms and conditions of the Creative Commons Attribution (CC BY) license (https:// creativecommons.org/licenses/by/ $4.0 /)$.

\begin{abstract}
In the present work, a Boussinesq-type numerical model is developed for the simulation of nonlinear wave-heaving cylinder interaction. The wave model is able to describe the propagation of fully dispersive and weakly nonlinear waves over any finite water depth. The wave-cylinder interaction is taken into account by solving simultaneously an elliptic equation that determines the pressure exerted by the fluid on the floating body. The heave motion for the partially immersed floating cylinder under the action of waves is obtained by solving numerically the body's equation of motion in the $z$ direction based on Newton's law. The developed model is applied for the case of a fixed and a free-floating circular cylinder under the action of regular waves, as well as for a free-floating cylinder undergoing a forced motion in heave. Results (heave and surge exciting forces, heave motions, and wave elevation) are compared with those obtained using a frequency domain numerical model, which is based on the boundary integral equation method.
\end{abstract}

Keywords: Boussinesq model; heaving cylinder; nonlinear wave-floating cylinder interaction

\section{Introduction}

Contemporary technological advances seek the efficient exploitation of the vast wave energy toward the transition of the European countries to a carbon-neutral energy future. Accordingly, the technology of wave energy converters (WECs) has been rapidly evolving during the last few years, with the aim of delivering commercially competitive solutions characterized by energy effectiveness, adequate structural integrity, and cost efficiency. Among the various types of WECs proposed or developed so far [1], heaving devices are considered nowadays one of the most advanced WEC technology [2].

The design of heaving WECs relies heavily on the utilization of conventional, computationally efficient, linear numerical models for assessing the hydrodynamic behavior and, thus, the power absorption ability of the device under the wave action in frequency or time domain. However, nonlinear effects existing in the real physical problem may become important (e.g., at nearshore locations or at resonance conditions), and therefore, the deployment of nonlinear numerical models for simulating the interaction of the heaving device with the waves is required. Along these lines, Boussinesq-type numerical models accurately predicting nonlinear nearshore hydrodynamics could be utilized.

In previous works, Boussinesq-type numerical models were employed to simulate the generation and propagation of ship-borne waves (e.g., [3-10]). The ship was represented as a moving pressure disturbance by incorporating a pressure term in the momentum equation. In a similar way, Bingham [11], Koutandos et al. [12], and Eskilsson et al. [13] used 1DH Boussinesq-type modeling equations to predict the wave-induced motion of a floating structure. In the above works, the pressure term was calculated in a simple way by considering a single static surface depression $[5,7-9]$ or in a more complicated way by solving simultaneously an additional equation (the Laplace equation, as in [12], or a depth-integrated momentum equation, as in [13]). Lannes [14] proposed together with 
the Boussinesq equations the simultaneous solution of an elliptic equation to determine the pressure exerted by the fluid on the floating body (see also [15]). Quite recently, a Boussinesq-type model has been developed in [16] for solving the problem of only the wave diffraction induced by a fixed truncated vertical cylinder.

With the aim of filling existing research gaps, the present paper highlights a $2 \mathrm{DH}$ Boussinesq-type numerical model with advanced features, developed for the simulation of nonlinear wave-heaving cylinder interaction. The model is based on the 2DH postBoussinesq model of Karambas and Memos [17], which is capable to describe the propagation of fully dispersive and weakly nonlinear waves over any finite water depth, and it has been applied in several research studies and engineering applications (indicative reference is made to $[18,19])$. The main advantage of the present nonlinear wave model is that it is a wavenumber-free model and, as far as the theoretical linear dispersion relation is concerned, the approach is exact. Thus, the model is able to describe the propagation of any nonlinear wave (or other sea surface disturbance) at any finite water depth. Following [14], the wave-cylinder interaction is taken into account by solving simultaneously an elliptic equation that determines the fluid pressure applied on the floating body. Newton's law is employed to form the body's equation of motion in the vertical direction, and, thus, calculate the heave motion of the cylinder. The developed model is applied for the case of a fixed and a free-floating circular cylinder under the action of regular waves, as well as for a free-floating circular cylinder undergoing a forced motion in heave. Results are compared with those obtained using WAMITC, which is based on the well-known boundary integral equation method (BIEM). It is worth noting that although the present approach is based on the post-Boussinesq model of [17], it can be also deployed in any other Boussinesq-type model.

The remainder of the paper is organized as follows: In Section 2, the 2DH postBoussinesq model is presented, together with the elliptic equation that determines the pressure exerted by the fluid on the floating body. In this section, the numerical scheme and the equation of the partially immersed body's heave motion under the action of waves are also described. In Section 3, the results of the present investigation are presented and discussed in detail, while, finally, in Section 4, the main conclusions of this study are cited along with suggestions for future investigation.

\section{The 2DH Post-Boussinesq Model}

\subsection{Model Equations}

The model's momentum equations were extracted adopting a methodology based on the Fourier transform, leading to equations similar to the respective ones for long waves, incorporating a single additional frequency dispersion term. The latter is expressed through convolution integrals, which are estimated using appropriate impulse functions. Accordingly, the momentum equations are expressed as follows [17]:

$$
\begin{aligned}
& \frac{\partial U}{\partial t}+U \frac{\partial U}{\partial x}+V \frac{\partial U}{\partial y}+g \frac{\partial \zeta}{\partial x}=-\int_{-\infty}^{\infty} \int_{-\infty}^{\infty}\left(\frac{\partial \zeta}{\partial x}\left(x-\xi_{1}, x-\xi_{2}, t\right)-\frac{\partial \zeta}{\partial x}\right) K\left(\xi_{1}, \xi_{2}\right) d \xi_{1} d \xi_{2}-\frac{1}{\rho} \frac{\partial P}{\partial x} \\
& \frac{\partial V}{\partial t}+U \frac{\partial V}{\partial x}+V \frac{\partial V}{\partial y}+g \frac{\partial \zeta}{\partial y}=-\int_{-\infty}^{\infty} \int_{-\infty}^{\infty}\left(\frac{\partial \zeta}{\partial y}\left(x-\xi_{1}, x-\xi_{2}, t\right)-\frac{\partial \zeta}{\partial y}\right) K\left(\xi_{1}, \xi_{2}\right) d \xi_{1} d \xi_{2}-\frac{1}{\rho} \frac{\partial P}{\partial y}
\end{aligned}
$$

where $U, V$ are, respectively, the depth-averaged velocity components along the $x$ and $y$ direction, $\rho$ is the water density, $\zeta$ is the free surface elevation, $g$ the gravitational acceleration, $t$ is time, and $P$ is the interior pressure exerted by the fluid on the bottom of the floating body. In Equations (1) and (2), the kernel $K(x, y)$ is given by [17] as:

$$
K(x, y)=\frac{g}{2 \pi d^{2}}\left[\frac{1}{r / d}-\sum_{n=1}^{\infty} \frac{(-1)^{n-1}}{\sqrt{n^{2}+(r / d)^{2} / 4}}\right]
$$

where $d$ is the water depth and $r=\sqrt{x^{2}+y^{2}}$. 
Equations (1) and (2) together with the continuity equation

$$
\frac{\partial \zeta}{\partial t}+\frac{\partial[(d+\zeta) U]}{\partial x}+\frac{\partial[(d+\zeta) V]}{\partial y}=0
$$

form the system of equations of the 2DH post-Boussinesq model.

The model is wavenumber free and, as far as the theoretical linear dispersion relation is concerned, the approach is exact (i.e., the model poses no restriction on the water depth). It also includes only a single frequency dispersion term to obtain the theoretical dispersion relation, while other Boussinesq-type models consider a significant number of terms with high order derivatives.

\subsection{The Pressure in the Interior Domain}

Due to the presence of the floating body, the horizontal plane is divided into two regions-the interior domain, defined as the projection of the wetted surface on the body, and the exterior domain. The interior pressure $P$ of the last terms of the right-hand side of Equations (1) and (2) is calculated by numerically solving the following elliptic equation according to [14]:

$\frac{1}{\rho} \frac{\partial\left(h \frac{\partial P}{\partial x}\right)}{\partial x}+\frac{1}{\rho} \frac{\partial\left(h \frac{\partial P}{\partial y}\right)}{\partial y}+\frac{\partial^{2} \zeta_{w}}{\partial t^{2}}+\frac{\partial(N L x)}{\partial x}+\frac{\partial(N L y)}{\partial y}+g \frac{\partial\left(h \frac{\partial \zeta}{\partial x}\right)}{\partial x}+g \frac{\partial\left(h \frac{\partial \zeta}{\partial y}\right)}{\partial y}=-\frac{\partial(h B T x)}{\partial x}-\frac{\partial(h B T y)}{\partial y}$

where $\zeta_{w}(x, y)$ is the local instantaneous draught of the floating body (i.e., the instantaneous hull's wetted surface and, consequently, the shape of a pressure disturbance), $h$ is the total water depth-namely, $h=d+\zeta$, NLx, and NLy are the nonlinear terms of the momentum equations (Equations (1) and (2)), whereas BTx and BTy are the dispersion terms (i.e., the integral terms) of Equations (1) and (2).

At the bottom boundary of the floating body, the following condition is applied:

$$
P=p_{\text {bouss }}
$$

where $p_{\text {bouss }}$ is the pressure on the body bottom, which is calculated by adopting the pressure distribution of the Boussinesq equations [12].

The terms NLx, NLy, BTx and BTy of Equation (5) are defined as follows:

$$
\begin{gathered}
N L x=U \frac{\partial h U}{\partial x}+V \frac{\partial h U}{\partial y} \\
N L y=U \frac{\partial h V}{\partial x}+V \frac{\partial h V}{\partial y} \\
B T x=\int_{-\infty}^{\infty} \int_{-\infty}^{\infty}\left(\frac{\partial \zeta}{\partial x}\left(x-\xi_{1}, x-\xi_{2}, t\right)-\frac{\partial \zeta}{\partial x}\right) K\left(\xi_{1}, \xi_{2}\right) d \xi_{1} d \xi_{2} \\
B T y=\int_{-\infty}^{\infty} \int_{-\infty}^{\infty}\left(\frac{\partial \zeta}{\partial y}\left(x-\xi_{1}, x-\xi_{2}, t\right)-\frac{\partial \zeta}{\partial y}\right) K\left(\xi_{1}, \xi_{2}\right) d \xi_{1} d \xi_{2}
\end{gathered}
$$

In the case of other types of classical Boussinesq equations, the dispersive terms BTx and BTy can be written as (assuming constant depth)

$$
\begin{aligned}
& B T x=\frac{d^{2}}{3} \frac{\partial^{3} U}{\partial t \partial x^{2}}+\frac{d^{2}}{3} \frac{\partial^{3} V}{\partial t \partial x \partial y} \\
& B T y=\frac{d^{2}}{3} \frac{\partial^{3} V}{\partial t \partial y^{2}}+\frac{d^{2}}{3} \frac{\partial^{3} U}{\partial t \partial x \partial y}
\end{aligned}
$$


Equation (5), as well as the pressure terms $\frac{\partial P}{\partial x}, \frac{\partial P}{\partial y}$ of Equations (1) and (2), respectively, were applied only in the interior computational domain, while in the exterior domain, zero surface (atmospheric) pressure was considered, i.e., $P=0$.

\subsection{Numerical Scheme}

The numerical solution was accomplished by a widely used simple and well-documented explicit second-order finite difference scheme, centered in space and forward in time on a staggered grid [17]. The scheme conserves mass and energy for nonbreaking waves in a satisfactory manner. The discrete continuity equation is centered in the level points and the momentum equations in the flux points.

The continuity and the momentum equations are approximated by finite difference equations according to the selected explicit scheme. The convolution integrals of Equations (1) and (2) are calculated numerically using higher-order methods [17].

The deployed finite differences scheme explicitly avoids the solution of a large system of algebraic equations, as in other Boussinesq formulations, which include a large number of terms.

The waves are generated inside the computational domain by simply adding a line source (a point source in the one-dimensional case) in the continuity equation [20]. Wave absorption at the open boundaries of the computational domain is achieved using the sponge layer technique according to [21].

\subsection{Floating Body Dynamics}

The equation of the heave motion for the partially immersed body's dynamics under the action of regular waves is described by Newton's law in the $z$ direction as follows:

$$
\left(M+M_{a}\right) \frac{d^{2} Z}{d t^{2}}+B \frac{d Z}{d t}+K Z=F_{\text {heave }}
$$

In Equation (13), $Z$ is the vertical displacement of the floating body, $M$ is the submerged mass of the body, $M_{a}$ is the heave added mass (hydrodynamic mass coefficient), $B$ is a heave damping coefficient resulting from various sources (e.g., viscous damping), $K$ is the heave hydrostatic restoring force coefficient, and $F_{\text {heave }}$ is the vertical exciting force. The latter quantity is obtained by integrating the interior pressure $P$ derived from the numerical solution of the elliptic equation (Equation (5)) over the wetted surface of the body $S$ as follows:

$$
F_{\text {heave }}=\iint_{S} P n_{z} d S
$$

where $n_{z}$ is the normal unit vector along $z$ direction.

In addition to the above, the horizontal (along $x$ ) exciting force, $F_{\text {surge, }}$, can be calculated as follows:

$$
F_{\text {surge }}=\iint_{S} p n_{x} d S
$$

where $p$ is the pressure on the body sides, calculated by adopting the pressure distribution of the Boussinesq equations [12], and $n_{x}$ is the normal unit vector along the $x$ direction.

In the case of a heaving circular cylinder with radius $a$ and draft (at rest) $b$, as examined in this investigation, the submerged mass $M$ is equal to $\rho \pi b a^{2}$ and its heave hydrostatic restoring force coefficient $K$ is equal to $\rho g \pi a^{2}$ [22]. As for $M_{a}$ (Equation (13)), this frequencydepended coefficient was obtained in the present paper using WAMITC (2006) code [23], which is based on the well-known BIEM. The relevant frequency domain linear hydrodynamic analysis under unit-amplitude regular waves assumes incompressible and inviscid fluid, as well as irrotational flow. Thus, the fluid motion is described by introducing the velocity potential, which satisfies the Laplace equation everywhere in the fluid domain. The corresponding boundary value problem is formed by imposing the well-known linearized boundary conditions on the free surface, on the sea bottom, and on the floating body [23,24]. The boundary integral equations for the unknown velocity potentials on the boundary 
of the body are formed utilizing Green's theorem, and the boundary value problem is solved by deploying a three-dimensional high-order panel method [23,24]. Subsequently, all physical quantities describing the hydrodynamic behavior of the floating body (e.g., heave exciting force and hydrodynamic coefficients, heave response, etc.) were calculated. It is worth noting that WAMIT $\odot$ was also deployed in the present paper in order to compare its results with those obtained from the $2 \mathrm{DH}$ post-Boussinesq model.

\section{Results and Discussion}

The 2DH post-Boussinesq model developed in this study was applied successively for three different cases of the examined physical problem. The first case considered a circular cylinder fixed at its position under the wave action and focused on the calculation of the surge and heave exciting forces applied on the body. The second one dealt with the waves generated by a free-floating circular cylinder undergoing a forced prescribed sinusoidal motion in heave. Finally, the third case focused on the heave responses of a freefloating circular cylinder under the action of waves. For the first and the last case, regular waves were taken into account, facilitating the comparison of results with those obtained using the BIEM model. Accordingly, all nonlinear terms in Equations (1), (2) and (4) were assumed to be equal to zero. Detailed characteristics of all the above cases along with the corresponding results are presented in the following sections. Regarding the computing resources required for the present model runs, indicatively, the computational time for a $50 \mathrm{~s}$ simulated time-run on a 500X500 node grid was $\sim 4$ hours on a desktop PC with 3.20 GHz Intel ${ }^{\mathrm{R}}$ Core $^{\mathrm{TM}} \mathrm{i} 7-3930 \mathrm{~K}$ processor and 32.0 GB installed RAM.

\subsection{Surge and Heave Exciting Forces on a Fixed Cylinder}

The surge and heave exciting forces were obtained for a fixed circular cylinder of radius $a=1.0 \mathrm{~m}$ and for different draft-to-radius ratios, $b / a$, equal to $0.5,1.0$, and 2.0. The cylinder was subjected to the action of unit-amplitude monochromatic waves of varying periods in deep water conditions. The corresponding results are shown in Figures 1 and 2, where the nondimensional amplitude of the surge, $\left|F_{\text {surge }}\right|$, and heave, $\left|F_{\text {heave }}\right|$, exciting forces (values are normalized by $\pi \rho g A a^{2}$, with $A$ denoting the amplitude of the incident wave) are plotted as a function of $k_{0} a$, where $k_{0}$ is the wavenumber in deep waters. The corresponding results derived by the BIEM are also included for comparison purposes.

In the case of the surge exciting force (Figure 1), the results of the present model for all $b / a$ values examined illustrate a smooth variation of this force with $k_{0} a$, with a peak value at $k_{o} a \sim 0.8$. For a given nondimensional wavenumber, the increase of the cylinder's draft leads, as expected, to larger surge exciting forces values. As for the heave exciting forces (Figure 2), the results of the 2DH post-Boussinesq model for a given $b / a$ ratio demonstrate a smooth decrease of the nondimensional $\left|F_{\text {heave }}\right|$ values with $k_{o} a$, starting from the limiting value of 1 as $k_{0} a \rightarrow 0$. On the other hand, the increase of $b / a$ leads, as expected, to smaller amplitudes of the heave exciting forces. All the above trends are in absolute accordance with the BIEM curves. Finally, the results obtained with the 2DH post-Boussinesq model agree quite well with those obtained using the BIEM model. More specifically, the average absolute difference between the $\left|F_{\text {surge }}\right|$ results of the two numerical models is equal to $0.03,0.03$, and 0.05 , respectively, for $b / a=0.5,1.0$, and 2.0, while in the case of the $\left|F_{\text {heave }}\right|$ results, it is equal to 0.03 for all $b / a$ ratios examined. The small differences can be attributed to the consideration of different assumptions in the two numerical models. 


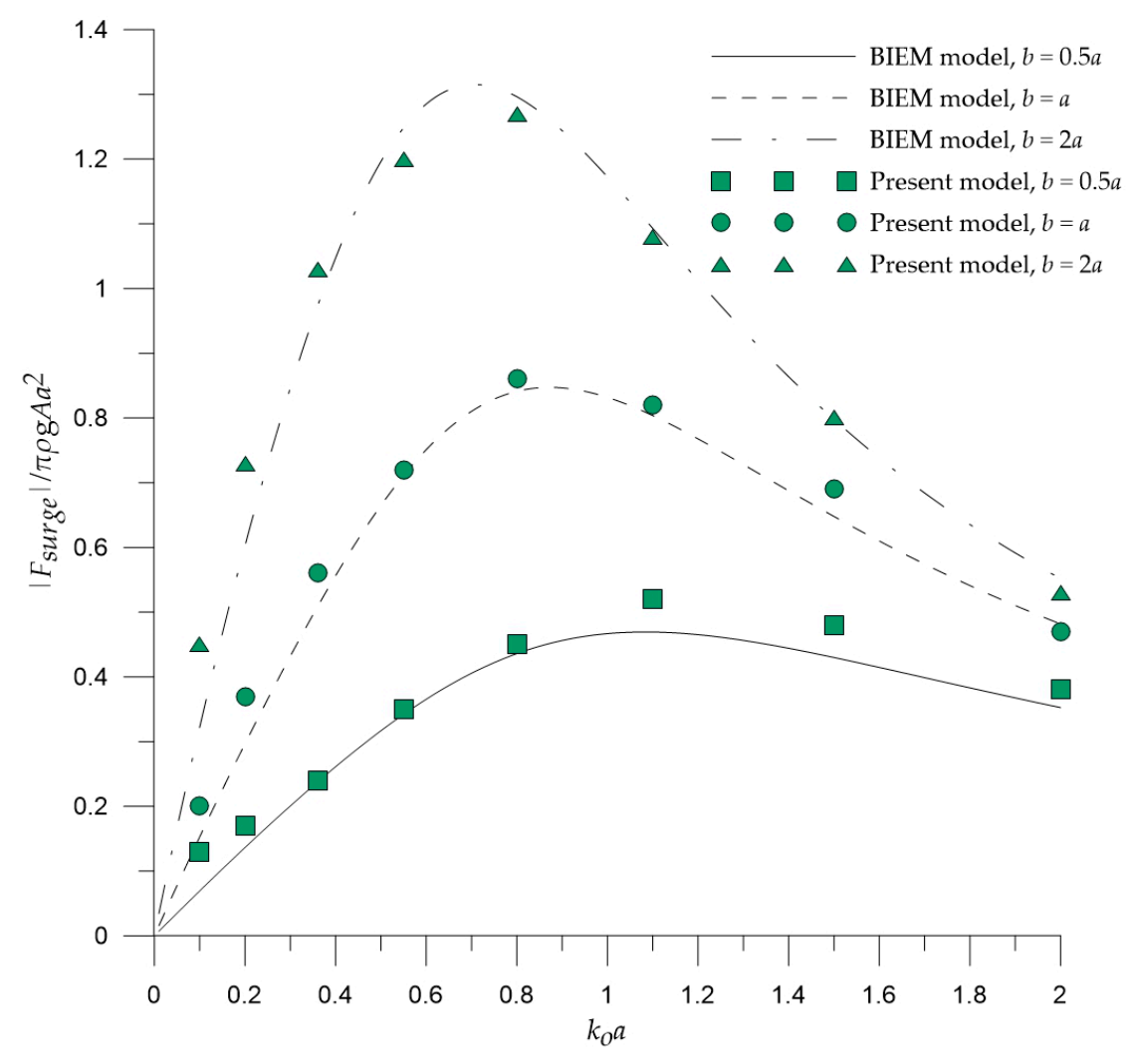

Figure 1. Variation of $\left|F_{\text {surge }}\right| / \pi \rho g A a^{2}$ as a function of $k_{0} a$ for different $b / a$ ratios (fixed circular cylinder).

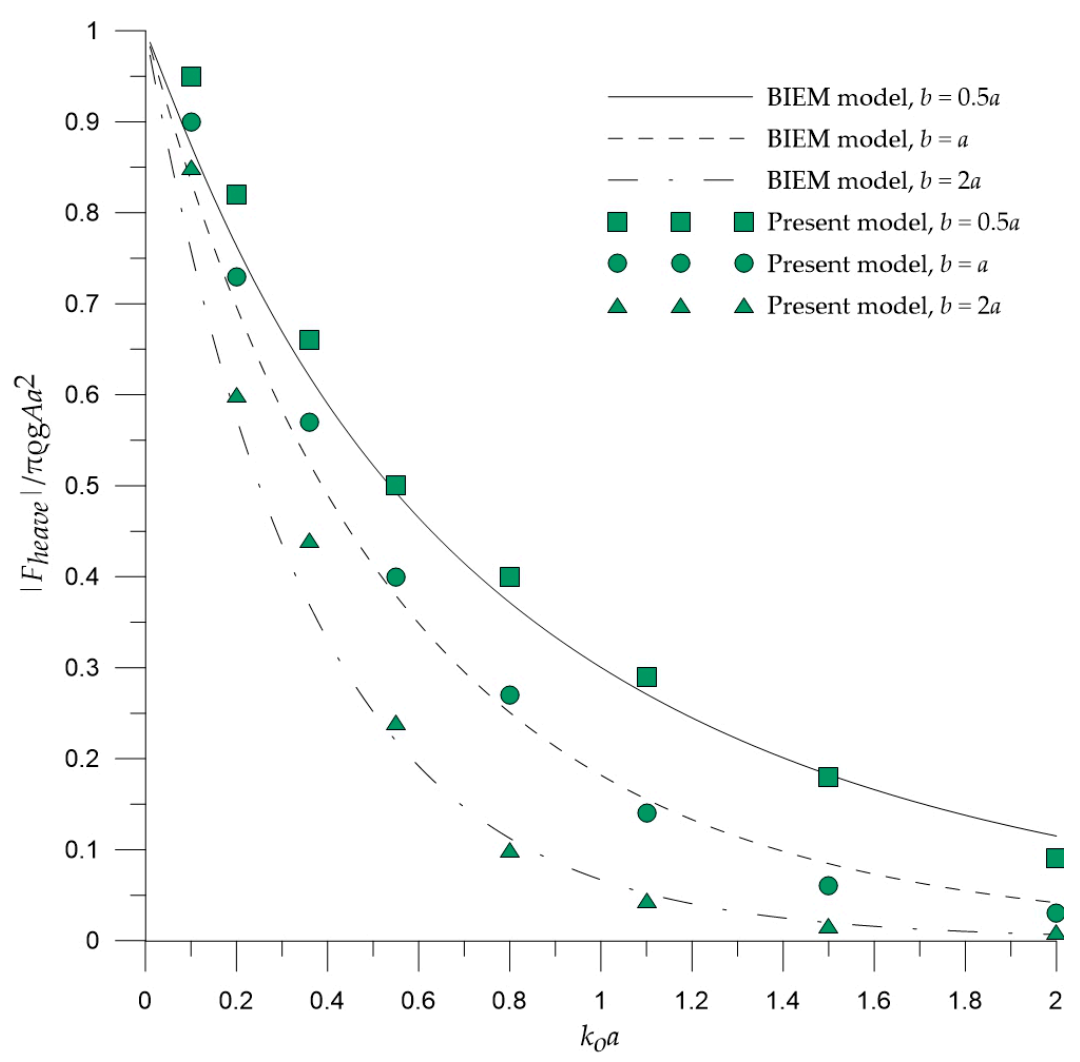

Figure 2. Variation of $\left|F_{\text {heave }}\right| / \pi \rho g A a^{2}$ as a function of $k_{o} a$ for different $b / a$ ratios (fixed circular cylinder). 


\subsection{Waves Generated by the Forced Heave Motion of a Free-Floating Cylinder}

In this section, we focus on the case of a free-floating circular cylinder undergoing a forced prescribed motion in heave. Initially, we considered a cylinder of $a=10.0 \mathrm{~m}$ and $b / a=0.5$, placed in an area of water depth, $d$, equal to $28 \mathrm{~m}$. The cylinder was subjected to a sinusoidal forced motion of $1.0 \mathrm{~m}$ amplitude and oscillation period, $T$, equal to $6 \mathrm{~s}$. Figure 3 shows the free-surface elevation around the cylinder due to the waves generated by the forced motion of the cylinder. A circular pattern of waves radiating energy in all directions around the cylinder can be easily identified, demonstrating the ability of the developed 2DH post-Boussinesq model to capture effectively the relevant aspects of the examined physical problem.

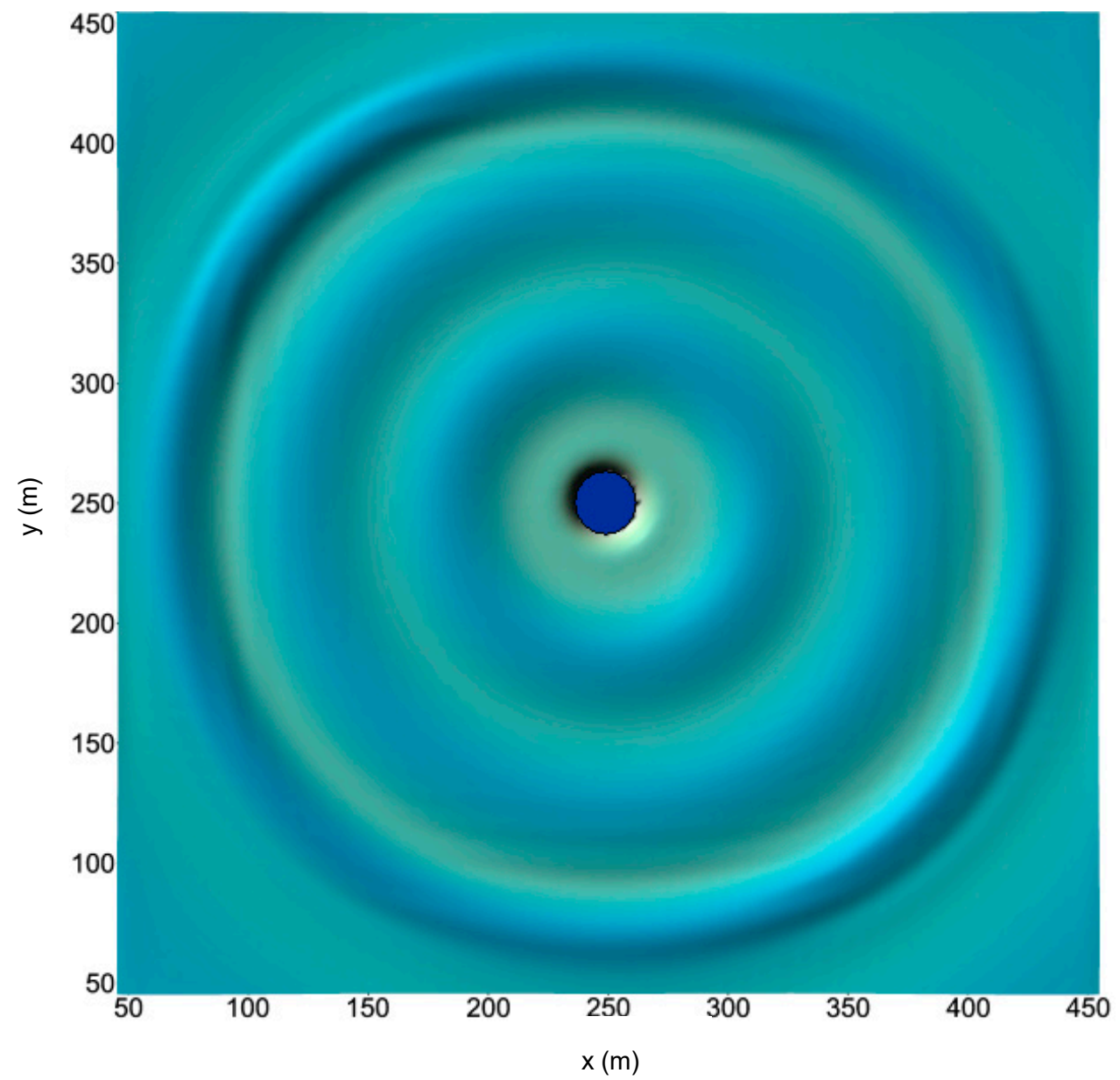

Figure 3. Perspective view of the free-surface elevation due to waves generated by a forced unitamplitude sinusoidal motion $(T=6 \mathrm{~s})$ in heave of a cylinder, with $a=10.0 \mathrm{~m}$ and $b / a=0.5$ placed at $d=28 \mathrm{~m}$.

In Figure 4, the amplitude of the free-surface elevation due to the waves generated by the forced motion of a cylinder of $a=5.0 \mathrm{~m}$ and $b / a=1.0$ are compared with those obtained using the BIEM. The floating cylinder was placed in an area of $d=10 \mathrm{~m}$, and it was subjected to a forced unit-amplitude sinusoidal motion of three different oscillation periods, $T$, equal to $5.6 \mathrm{~s}$ (coinciding with the cylinder's heave natural period, $T_{n}$ ), $8.0 \mathrm{~s}$ and $10.0 \mathrm{~s}$. In Equation (13), $B$ is assumed to be equal to 0, while the values of $M_{a}$ acquired from the BIEM model are given in nondimensional forms in Table 1. In this table, nondimensional $M_{a}$ values for $T=4.0 \mathrm{~s}, 6.0 \mathrm{~s}$, and $12.0 \mathrm{~s}$ utilized in the examined problem of Section 3.3 are also included. The free-surface elevation is calculated along a line parallel to the $x$ axis, passing the center of the cylinder. 


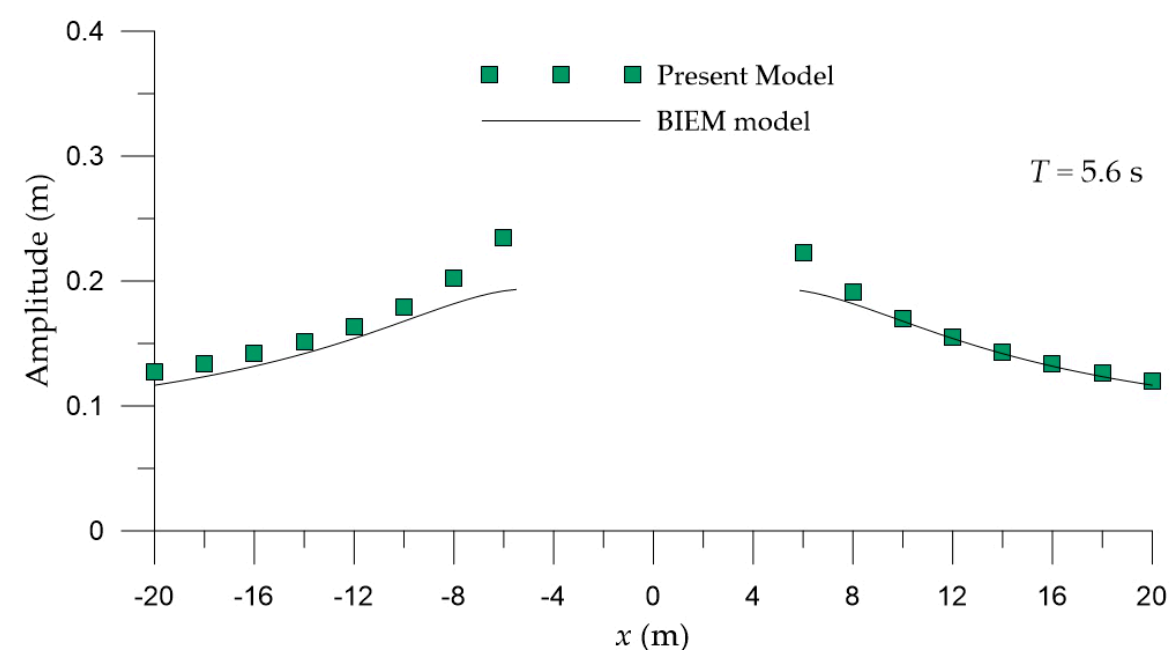

(a)

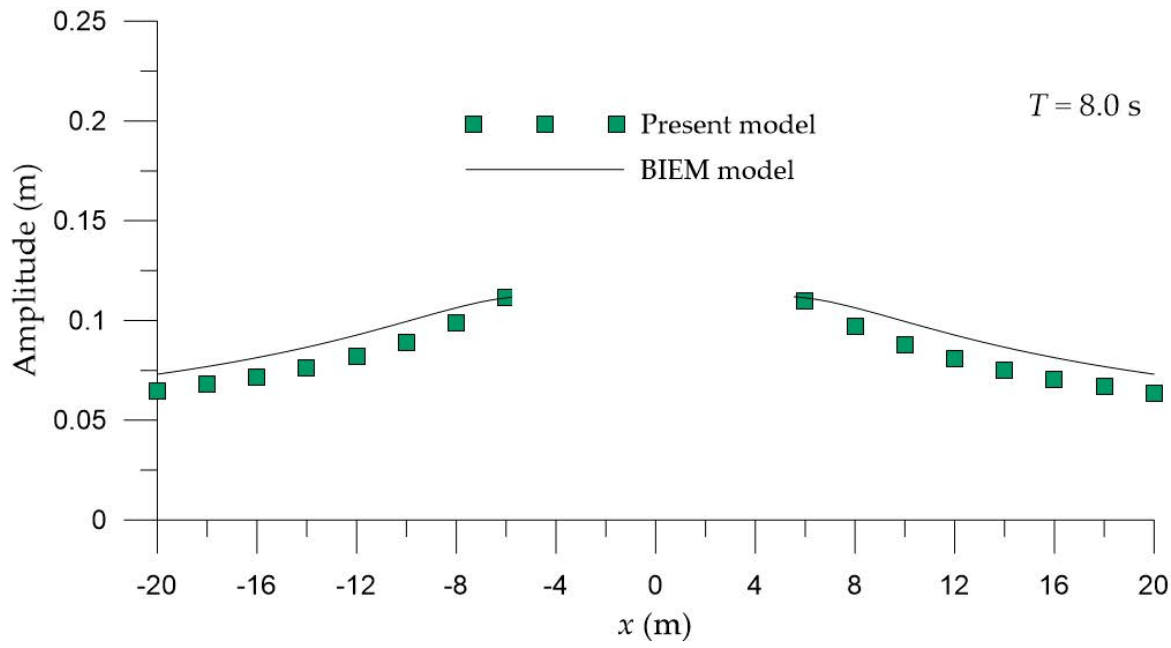

(b)

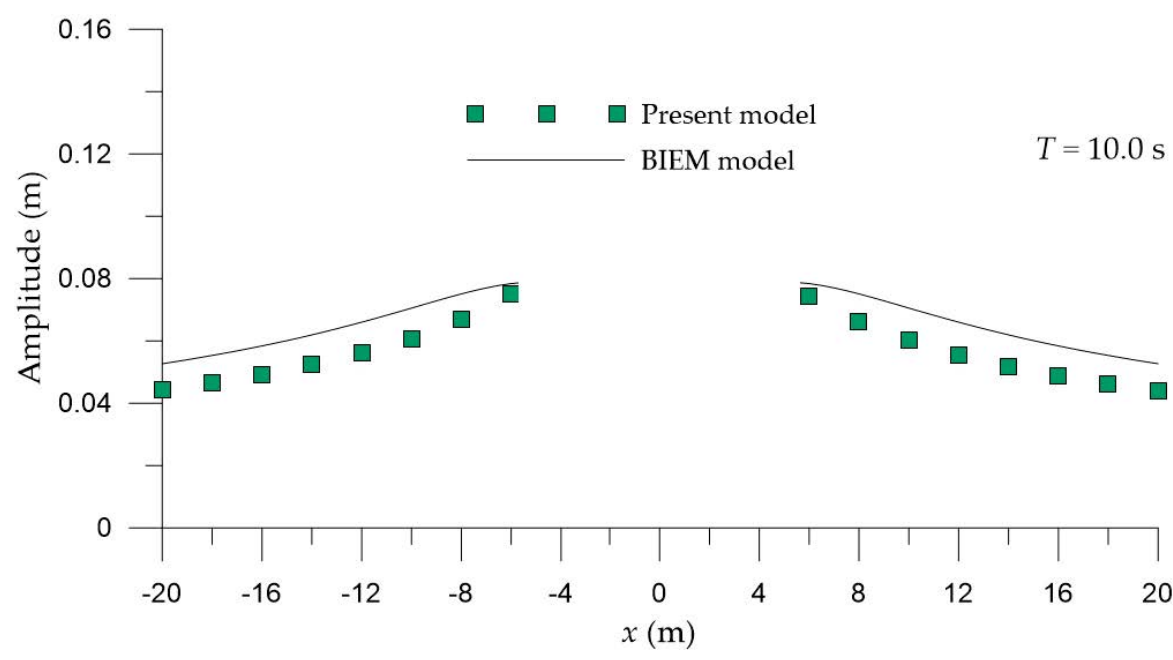

(c)

Figure 4. Variation of free-surface amplitude along the $x$ axis due to waves generated by a forced unitamplitude sinusoidal motion in heave of a cylinder with $a=5.0 \mathrm{~m}$ and $b / a=1.0$ placed at $d=10 \mathrm{~m}$ : (a) $T=5.6 \mathrm{~s}$; (b) $T=8.0 \mathrm{~s} ;$ (c) $T=10.0 \mathrm{~s}$. In all plots, the cylinder lies at $-5.0 \mathrm{~m} \leq x \leq 5.0 \mathrm{~m}$. 
Table 1. Nondimensional $M_{a}$ values for different oscillation periods for a cylinder of $a=5.0 \mathrm{~m}$ and $b / a=1.0$ placed at $d=10 \mathrm{~m}$.

\begin{tabular}{cc}
\hline $\boldsymbol{T}(\mathbf{s})$ & $\boldsymbol{M}_{\boldsymbol{a}} / \boldsymbol{\rho} \boldsymbol{a}^{3}$ \\
\hline 4.0 & 1.819 \\
5.6 & 1.804 \\
6.0 & 1.836 \\
8.0 & 2.032 \\
10.0 & 2.218 \\
12.0 & 2.377 \\
\hline
\end{tabular}

For both numerical models, the results of Figure 4 demonstrate a gradual decrease of the free-surface elevation, as we are moving away from the floating body. In the case of $T=5.6 \mathrm{~s}$, the results of the $2 \mathrm{DH}$ post-Boussinesq model agree well with the corresponding ones obtained using the BIEM model (absolute differences $\leq 0.02 \mathrm{~m}$ at $x<-6.0 \mathrm{~m}$ and $x>6.0 \mathrm{~m}$ ), except at locations close to the sides of the cylinder, where the former model leads to a bit larger values of the free-surface elevation, compared with the BIEM model (absolute differences equal to $0.04 \mathrm{~m}$ and $0.03 \mathrm{~m}$, respectively, at $x=-6.0 \mathrm{~m}$ and $x=6.0 \mathrm{~m}$ ). For $T=8 \mathrm{~s}$ and $10.0 \mathrm{~s}$, slightly smaller values are observed in the case of the $2 \mathrm{DH}$ postBoussinesq model, compared with the BIEM model (absolute differences $\leq 0.04 \mathrm{~m}$ and $\leq 0.01 \mathrm{~m}$, respectively for $T=8 \mathrm{~s}$ and $10.0 \mathrm{~s}$ ). As in the case of the exciting forces, all the above small differences can be attributed to the consideration of different assumptions in the two numerical models.

\subsection{Heave Motion of a Cylinder under Regular Waves}

In this section, we consider the case of a free-floating circular cylinder under the action of regular waves. Two cylinders of different geometrical characteristics were examined. The first cylinder had $a=5.0 \mathrm{~m}$ and $b / a=1.0(b=5.0 \mathrm{~m})$, and it was situated at an area of water depth $d=10 \mathrm{~m}$. It was subjected to unit-amplitude regular waves of six different wave periods, $T$, equal to $4.0 \mathrm{~s}, 5.6 \mathrm{~s}, 6.0 \mathrm{~s}, 8.0 \mathrm{~s}, 10.0 \mathrm{~s}$, and $12.0 \mathrm{~s}$. The second geometry corresponded to a cylinder of $a=10.0 \mathrm{~m}$ and $b / a=1.0(b=10.0 \mathrm{~m})$, which was placed at an area of $d=20 \mathrm{~m}$. For this cylinder, $T_{n}$ was calculated equal to $8.0 \mathrm{~s}$. The action of unit-amplitude regular waves of five different wave periods, $T$, equal to $4.0 \mathrm{~s}, 6.0 \mathrm{~s}, 8.0 \mathrm{~s}$, $10.0 \mathrm{~s}$, and $12.0 \mathrm{~s}$ was taken into account. For solving Equation (13) the values of $M_{a}$ of Tables 1 and 2 were taken into account for the cylinder with $a=5.0 \mathrm{~m}$ and $a=10.0 \mathrm{~m}$, respectively, while $B$ was assumed to be equal to 0 .

Table 2. Nondimensional $M_{a}$ values for different oscillation periods for a cylinder of $a=10.0 \mathrm{~m}$ and $b / a=1.0$ placed at $d=20 \mathrm{~m}$.

\begin{tabular}{cc}
\hline $\boldsymbol{T}(\mathbf{s})$ & $\boldsymbol{M}_{\boldsymbol{a}} / \rho \boldsymbol{a}^{3}$ \\
\hline 4.0 & 1.992 \\
6.0 & 1.795 \\
8.0 & 1.808 \\
10.0 & 1.938 \\
12.0 & 2.079 \\
\hline
\end{tabular}

Figure 5 shows the variation of the amplitude of the heave motion as a function of $T$ for the two examined cylinders. Starting with the smallest cylinder (Figure 5a), a peak of the heave motion occurs at $T=5.6 \mathrm{~s}$, attributed to resonance phenomena. Then, by increasing the incident wave period, the values of the cylinder's motion are successively decreased. Analogous is the variation of the heave motion in the case of the largest examined cylinder (Figure 5b). However, maximization of the heave motion due to resonance occurs at $T=8.0 \mathrm{~s}$, which coincides with the heave natural period of this cylinder. Compared with the BIEM model, the results of the present model show excellent agreement with those 
obtained deploying the BIEM model (absolute differences $<0.15 \mathrm{~m}$ ), except at the wave period range, where resonance phenomena occur. Specifically, at $T=5.6 \mathrm{~s}$ and $6.0 \mathrm{~s}$ in the case of the smallest cylinder (Figure 5a), as well as at $T=8.0 \mathrm{~s}$ for the largest examined cylinder (Figure $5 b$ ), the amplitude of the heave motion calculated with the present model has smaller values, compared with those of the BIEM model (absolute differences equal to $0.97 \mathrm{~m}, 0.62 \mathrm{~m}$ and $0.90 \mathrm{~m}$, respectively). This can be related to the different approaches of the two models and to the numerical round-off and truncation errors introduced in the numerical schemes of the present model (in the solution of both the hydrodynamic and motion equations).

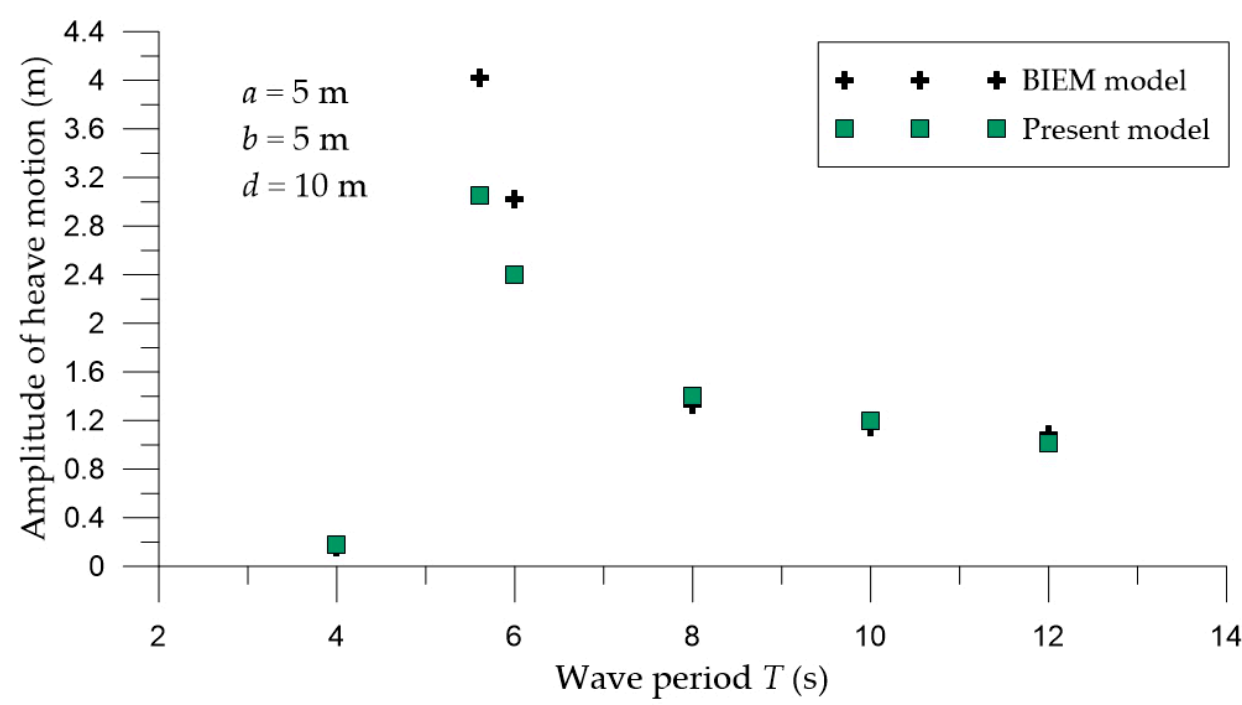

(a)

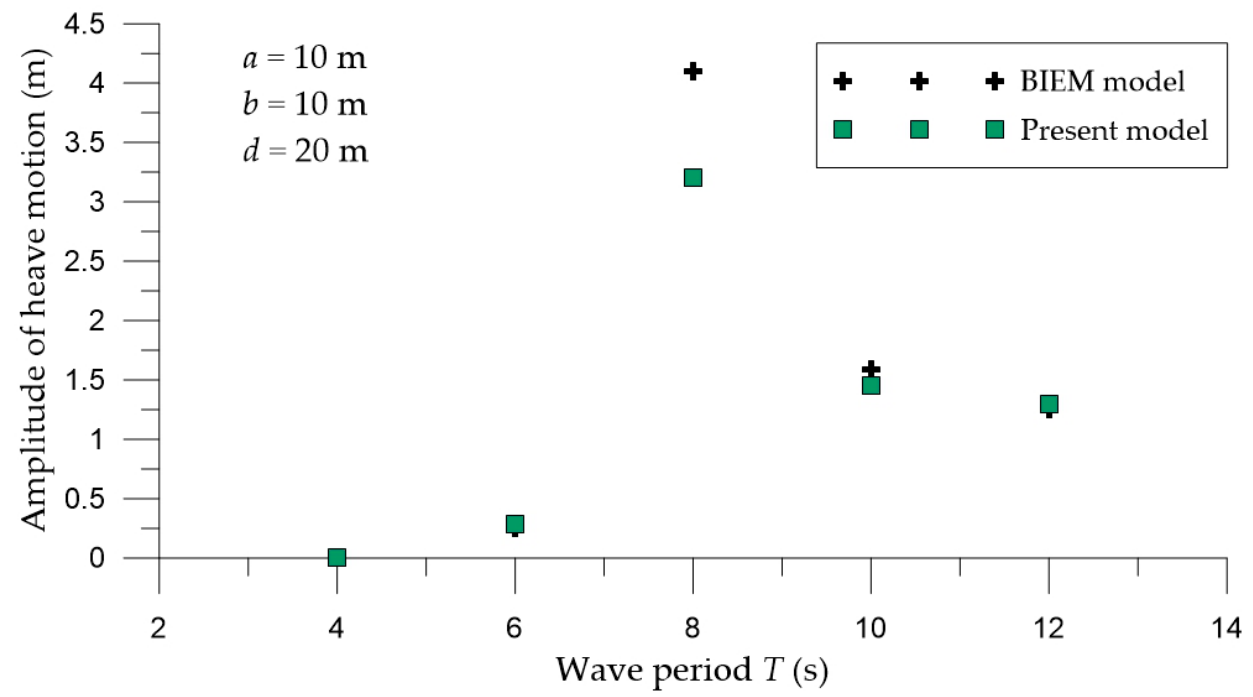

(b)

Figure 5. Amplitude of the cylinder's heave motion under regular waves: (a) $a=5.0 \mathrm{~m}$ and $b / a=1.0$ $(d=10.0 \mathrm{~m}) ;(\mathbf{b}) \alpha=10.0 \mathrm{~m}$ and $b / a=1.0(d=20.0 \mathrm{~m})$.

Figure 6 includes a perspective view of the free-surface elevation around the cylinder of $a=5.0 \mathrm{~m}$ and $b / a=1.0$ and for $T=8.0 \mathrm{~s}$. The disturbance of the incident waves due to scattering effects, but mainly due to the waves radiating from the motion of the cylinder, can be easily identified. This, in turn, demonstrates the ability of the model developed in the present investigation to capture effectively the main aspects of the examined physical problem. 


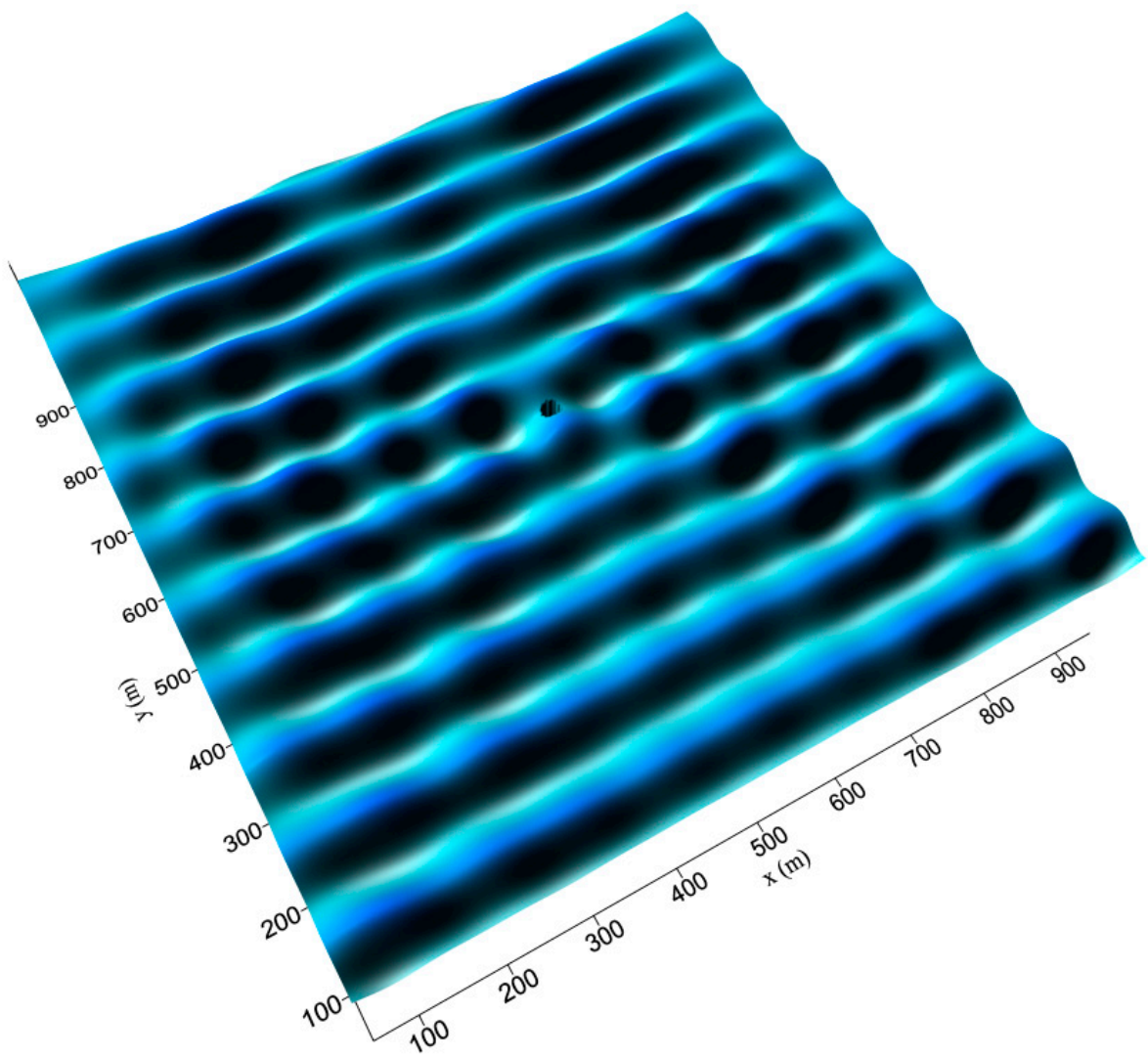

Figure 6. Perspective view of the free-surface elevation around a cylinder of $a=5.0 \mathrm{~m}$ and $b / a=1.0$ situated at $d=10 \mathrm{~m}$ under the action of unit-amplitude regular waves of $T=8.0 \mathrm{~s}$.

As already mentioned, in all the above results, the linear version of the present model was applied in order to compare results with those obtained using the BIEM model. However, for demonstrating the effects of nonlinear waves on the dynamic behavior of the floating cylinder, in Figure 7, nonlinear model results (nondimensional heave force and heave motion) are shown. The results are indicatively obtained for the cylinder with $a=5.0$ and $b / a=1.0$ under the action of unit-amplitude nonlinear monochromatic waves of $T=6.0 \mathrm{~s}$. It is obvious that both the heave force and motion are not purely sinusoidal, indicating the existence of nonlinear effects.

Finally, the heave responses of the aforementioned cylinder were calculated for nonlinear monochromatic waves of height, $H$, equal to $4.0 \mathrm{~m}$, and period $T$, equal to $4.0 \mathrm{~s}$, $5.6 \mathrm{~s}, 6.0 \mathrm{~s}, 8.0 \mathrm{~s}, 10.0 \mathrm{~s}$, and $12.0 \mathrm{~s}$. The corresponding results are shown in Figure 8, in which the maximum heave displacement minus the minimum one over the wave height (i.e., $\left(Z_{\max }-Z_{\max }\right) / H$ ) is plotted against $T$. In this figure, the results of Figure $5 \mathrm{a}$ are also included for illustrating the effect of the wave steepness on the vertical displacements of the cylinder. It can be seen that the action of nonlinear (steep) waves leads to smaller vertical displacements of the cylinder, especially in the period range, where resonance phenomena occur. However, the differences between the examined linear and nonlinear waves are not so significant. 


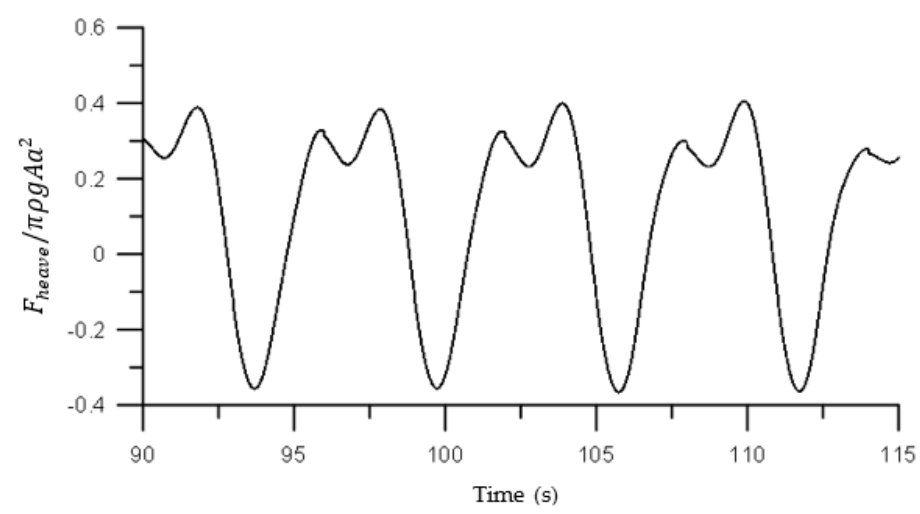

(a)

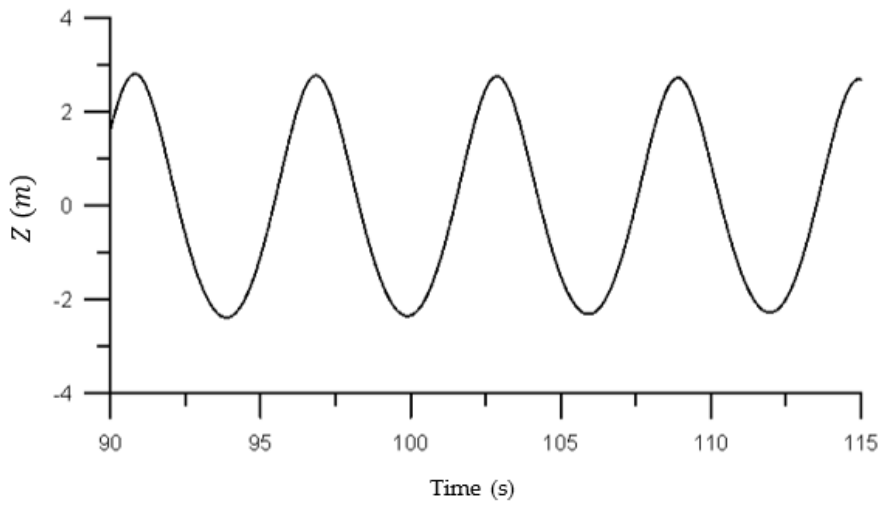

(b)

Figure 7. Time variation of the heave exciting force (a) and the heave motion (b) for the cylinder with $a=5.0 \mathrm{~m}$ and $b / a=1.0(d=10.0 \mathrm{~m})$ under the action of unit-amplitude nonlinear monochromatic waves of $T=6.0 \mathrm{~s}$.

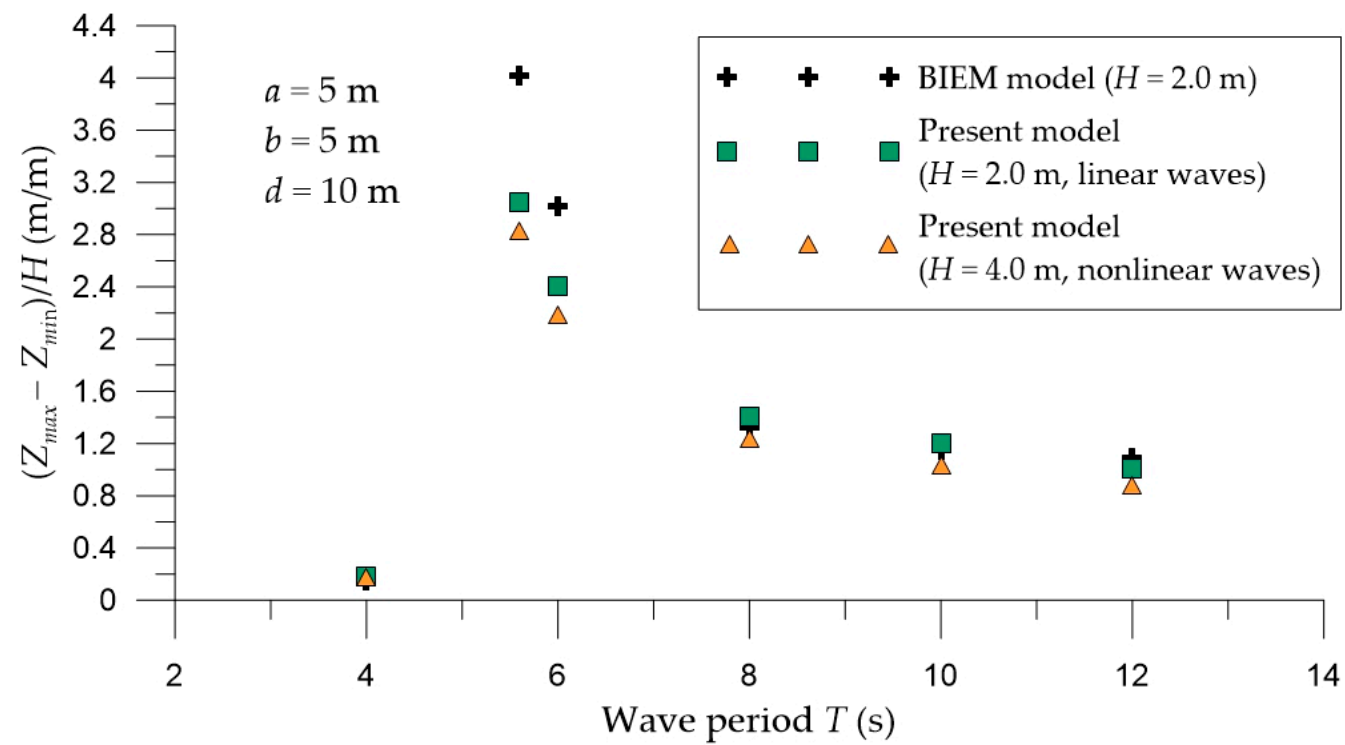

Figure 8. Nondimensional vertical displacement of a cylinder with $a=5.0 \mathrm{~m}$ and $b / a=1.0$ $(d=10.0 \mathrm{~m})$ under linear and nonlinear monochromatic waves. 


\section{Conclusions}

In the present work, a 2DH post-Boussinesq numerical model for the simulation of nonlinear wave-heaving cylindrical interaction was developed and presented. The model is able to describe the propagation of any nonlinear wave or other sea surface disturbance at any finite water depth, while the wave-cylinder interaction was taken into account by solving simultaneously an elliptic equation that determines the fluid pressure applied on the floating body. The model was applied for three different cases of a circular cylinder (a fixed and a free-floating cylinder under the action of regular waves, and a free-floating cylinder undergoing a forced motion in heave) in order to (a) compare results with those obtained using a BIEM model and (b) demonstrate the ability of the model to capture effectively the main aspects of the examined physical problem.

In the case of a fixed circular cylinder under the action of regular waves, the results of the $2 \mathrm{DH}$ post-Boussinesq model efficiently illustrated the foreseen effects of the nondimensional wavenumber and the nondimensional cylinder's draft on the heave and surge exciting forces. Similarly, the developed numerical model effectively captured the anticipated features of the wave elevation and the heave response variation for a freefloating circular cylinder under a forced motion in heave and under the action of regular waves, respectively.

For all cases examined, the results of the $2 \mathrm{DH}$ post-Boussinesq model showed very good agreement with those obtained using the BIEM model. The most pronounced differences were observed in the case of the heave response of the free-floating circular cylinder under the wave action at the wave period range, where resonance phenomena occur. In this period range, numerical round-off and truncation errors introduced in the numerical schemes of the present model (in the solution of both the hydrodynamic and motion equations) led to smaller values of the heave motion, compared with those of the BIEM model.

The present model requires much more computational time, compared with the applied BIEM model. However, it has the advantage of simulating both near- and farfield (propagation) effects of heaving cylinders over a variable bathymetry, as well as the interaction of these structures with nonlinear irregular waves.

Along these lines, the present model could be deployed in order to assess the performance of a heaving WEC under the action of nonlinear regular and/or irregular waves, by introducing the power take-off system forces in the equation of motion. The model could be also further extended to deal with arrays of heaving cylinders or WECs, enabling the assessment of the impacts of these multi-body configurations on the surrounding wave field, especially, at nearshore locations.

Author Contributions: Conceptualization, T.K. and E.L.; methodology, T.K. and E.L.; software, T.K. and E.L.; validation, T.K. and E.L.; formal analysis, T.K. and E.L.; investigation, T.K. and E.L.; writingoriginal draft preparation, T.K. and E.L. All authors have read and agreed to the published version of the manuscript.

Funding: This research received no external funding.

Institutional Review Board Statement: Not applicable.

Informed Consent Statement: Not applicable.

Conflicts of Interest: The authors declare no conflict of interest.

\section{References}

1. Rusu, E.; Onea, F. A review of the technologies for wave energy extraction. Clean Energy 2018, 2, 10-19. [CrossRef]

2. Magagna, D.; Monfardini, R.; Uihlein, A. JRC Ocean Energy Status Report, 2016th ed.; EUR 28407 EN (JRC104799); Publications Office of the European Union: Luxembourg, 2016; pp. 10-13.

3. Ertekin, R.; Webster, W.; Wehausen, J. Waves caused by a moving disturbance in a shallow channel of finite width. J. Fluid Mech. 1986, 169, 275-292. [CrossRef] 
4. Henn, R.; Jiang, T.; Sharma, S.D. Waves and forces caused by oscillations of a floating body determined through a unified nonlinear shallow-water theory. In Proceedings of the 23rd Symposium on Naval Hydrodynamics, Val de Reuil, France, 17-22 September 2000; pp. 993-1005.

5. Liu, P.L.-F.; Wu, T.-R. Waves generated by moving pressure disturbances in rectangular and trapezoidal channels. J. Hydraul. Res. 2004, 42, 163-171. [CrossRef]

6. Torsvik, T.; Pedersen, G.; Dysthe, K. Influence of Cross Channel Depth Variation on Shipwave Patterns. Mech. Appl. Math. 2008, 2, $1-23$.

7. Bayraktar Ersan, D.; Beji, S. Numerical simulation of waves generated by a moving pressure field. Ocean Eng. 2013, 59, 231-239. [CrossRef]

8. David, C.G.; Roeber, V.; Goseberg, N.; Schlurmann, T. Generation and propagation of ship-borne waves-Solutions from a Boussinesq-type model. Coast. Eng. 2017, 127, 170-187. [CrossRef]

9. Shi, F.; Malej, M.; Smith, J.; Kirby, J. Breaking of ship bores in a Boussinesq-type ship-wake model. Coast. Eng. 2018, 132, 1-12. [CrossRef]

10. Samaras, A.; Karambas, T. Numerical simulation of ship-borne waves using a 2DH post-Boussinesq model. Appl. Math. Model. 2021, 89, 1547-1556. [CrossRef]

11. Bingham, H. A hybrid Boussinesq-panel method for predicting the motion of a moored ship. Coast. Eng. 2000, 40, 21-38. [CrossRef]

12. Koutandos, E.; Karambas, T.; Koutitas, C. Floating breakwater response to waves action using a Boussinesq model coupled with a 2DV elliptic solver. J. Waterw. Port Coast. Ocean Eng. 2004, 130, 243-255. [CrossRef]

13. Eskilsson, C.; Palm, J.; Engsig-Karup, A.-P.; Bosi, U.; Ricchiuto, M. Wave induced motions of point-absorbers: A hierarchical investigation of hydrodynamic models. In Proceedings of the 11th European Wave and Tidal Energy Conference (EWTEC), Nantes, France, 6-11 September 2015. 9p.

14. Lannes, D. On the dynamics of floating structures. Ann. PDE 2017, 3, 11. [CrossRef]

15. Bocchi, E. Floating structures in shallow water: Local well-posedness in the axisymmetric case. SIAM J. Math. Anal. 2020, 52, 306-339. [CrossRef]

16. Mohapatra, S.C.; Islam, H.; Soares Guedes, C. Boussinesq model and CFD simulations of non-linear wave diffraction by a floating vertical cylinder. J. Mar. Sci. Eng. 2020, 8, 575. [CrossRef]

17. Karambas, T.V.; Memos, C.D. Boussinesq model for weakly nonlinear fully dispersive water waves. J. Waterw. Port Coast. Ocean Eng. 2009, 135, 187-199. [CrossRef]

18. Klonaris, G.T.; Memos, C.D.; Karambas, T.V. A Boussinesq-type model including wave-breaking terms in both continuity and momentum equations. Ocean Eng. 2013, 57, 128-140. [CrossRef]

19. Samaras, A.G.; Karambas, T.; Archetti, R. Simulation of tsunami generation, propagation and coastal inundation in the Eastern Mediterranean. Ocean Sci. 2015, 11, 643-655. [CrossRef]

20. Larsen, J.; Dancy, H. Open boundaries in short wave simulations-A new approach. Coast. Eng. 1983, 7, 285-297. [CrossRef]

21. Yoon, S.-B.; Choi, J.-W. A note on extension of fully dispersive weakly nonlinear wave equations for rapidly varying topography. Coast. Eng. J. 2001, 43, 143-160. [CrossRef]

22. Ghadimi, P.; Bandari, H.P.; Rostami, A.B. Determination of the heave and pitch motions of a floating cylinder by analytical solution of its diffraction problem and examination of the effects of geometric parameters on its dynamics in regular waves. Int. J. Appl. Math. 2012, 1, 611-633. [CrossRef]

23. WAMIT Theory Manual. Available online: https://www.wamit.com/Publications/tmanual.pdf (accessed on 25 October 2021).

24. Lee, C.H.; Newman, J.N. Computation of wave effects using the panel method. In Numerical Models in Fluid-Structure Interaction; Chakrabarti, S., Ed.; WIT Press: Southampton, UK, 2005; pp. 211-251. 